\title{
Cognitive Predictors of the Value of One's Own Life in Students
}

\section{Когнитивные предикторы ценности собственной жизни у студентов}

\section{Marat Kuznietsov}

Dr. in Psychology, Professor at the Department of Psychology, H. S. Skovoroda Kharkiv National Pedagogical University, Kharkiv (Ukraine)

ORCID ID: https://orcid.org/0000-0001-7662-9938

E-mail:marat704@ukr.net

\section{Марат Кузнецов}

Доктор психологических наук, профессор кафедры психологии, Харьковский национальный педагогический университет имени Г. С. Сковороды, г. Харьков (Украина)

\section{Nabil Diab}

Postgraduate Student at the Department of Psychology, H. S. Skovoroda Kharkiv National Pedagogical University, Kharkiv (Ukraine)

ORCID ID: https://orcid.org/0000-0002-5909-9485

E-mail: nabil.diab@hotmail.com

\section{Набил Диаб}

Аспирант кафедры психологии, Харьковский национальный педагогический университет имени Г. С. Сковороды, г. Харьков (Украина)

Address for correspondence, e-mail: kpnu_lab_ps@ukr.net Copyright: (C) Kuznietsov Marat, Diab Nabil

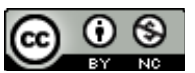

The article is licensed under CC BY-NC 4.0 International

(https://creativecommons.org/licenses/by-nc/4.0/)

(C) Kuznietsov Marat, Diab Nabil

DOI (article): https://doi.org/10.32626/2227-6246.2020-48.175-205 
DOI: https://doi.org/10.32626/2227-6246.2020-48 2020. випуск 48

The author's contribution: M. Kuznietsov - 50\%, N. Diab - 50\%.

Авторский вклад: М. Кузнецов - 50\%, Н. Диаб - 50\%.

\section{ABSTRACT}

The aim of the article is to present the findings of the empirical research on the feeling of the value of one's own life (VOL) in students. Experiencing the feeling of VOL is understood to be the intended activity of an individual through which they reinforce (strengthen) their psychological and personal being. A presumption about the important role of a cognitive factor in experiencing the feeling of VOL in students was tested. In the manifestation of VOL, the role of such a cognitive factor as basic beliefs was investigated.

Methods. Basic beliefs were diagnosed using the modified questionnaire by $R$. Janoff-Bulman. To diagnose the parameters of the feeling of VOL, the author's questionnaire was used. 286 students took part in the testing. The correlations between the scores of two questionnaires were calculated. Logistic regression was used.

The results of the research. Parameters of the feeling of VOL such as "Optimism», "Health", "Self-control, Information, Self-development», "Power, Status, Wealth" and "Close relationships, Family, Relevance» turned out to be closely related to measures of basic beliefs. This is especially true of beliefs about justice, a positive self-image, control, goodwill. Age-related differences in the structure of correlations between the measures were revealed. For senior students, experiencing the feeling of $\mathrm{VOL}$ as possessing power, status and wealth is more closely linked to a basic belief about justice than for junior students. Concerning health, they often note the importance of control. When assessing the role of the family and close relationships senior students rely less on good luck than junior students.

Two modes of experiencing the feeling of $\mathrm{VOL}$ were singled out, the "Building rapport with people» mode and the "Distancing from people» mode. Using the logistic regression, the probability was calculated with which the students' tendency to build rapport with people would prevail over the students' tendency to distance from people. As predictors, the regression equation included the measures of the basic belief questionnaire.

Conclusions. It is proved that the predominance of the tendency of building rapport over the tendency of distancing when experiencing the feeling of $\mathrm{VOL}$ in students is determined by three cognitive predictors. These are beliefs about (C) Kuznietsov Marat, Diab Nabil

DOI (article): https://doi.org/10.32626/2227-6246.2020-48.175-205 http://journals.uran.ua/index.php/2227-6246 
justice, about the control of the action and about a positive self-image. Beliefs about the goodwill of the surrounding community and about good luck were not included in the list of influential cognitive predictors for the feeling of VOL.

Key words: value of one's own life, feeling of the value of one's own life, cognitive predictor of the feeling of the value of one's own life, parameters of the value of one's own life, modes of experiencing the feeling of the value of one's own life in students, basic beliefs.

\section{Вступление}

Ценность собственной жизни (далее - ЦСЖ ) - многомерный, системный регулятор поведения и деятельности человека. Он формируется прижизненно и расположен на вершинных уровнях ценностной иерархии личности. Как правило, люди без особых затруднений могут привести рациональные доводы относительно того, почему они ценят свою жизнь. Когнитивной основой чувства ЦСЖ являются суждения человека о своей жизни в целом (о ее качестве, содержательной наполненности, динамике, направленности). Это также суждения о том, что придает смысл его жизни. Способность адекватно проявлять чувство ЦСК свидетельствует о психологическом здоровье человека, включенности в конструктивные связи с социумом.

Проявление ЦСЖ не подчиняется правилу «все, или ничего». На определенных этапах своей жизни люди отмечают заметное снижение, и даже искажение чувства ЦСЖ. Это может быть обусловлено разными причинами (болезнью, профессиональным выгоранием, возрастными кризисами, социальными потрясениями, утратой близких, имущества, вынужденной миграцией и т. п.). В самоотчетах такие периоды жизни описываются как «скучные и бесполезные», как «напрасно потраченное время», как «время ошибок и проступков», как «период жизни, за который очень стыдно», как «жизнь, за которую сейчас приходится расплачиваться» и т. п. Р. Джонсон и Дж. Руль связывают частичную утрату чувства ЦСЖ с так называемой «непрожитой

(C) Kuznietsov Marat, Diab Nabil DOI (article): https://doi.org/10.32626/2227-6246.2020-48.175-205 
жизнью", т. е. с накоплением в биографической памяти субъекта множества вариантов жизни, которые были в свое время отвергнуты, но не утратили своей привлекательности (Джонсон \& Руль, 2017).

Э. Шпрангер подчеркивал, что жизнь в условиях современной культуры приводит к нескольким вариантам переживания чувства ЦСЖ. Он описал 6 «идеальных типов индивидуальности». Каждый из типов (теоретический, экономический, эстетический, социальный, властный и религиозный) строится на некоторой смысловой основе, которая может быть рационально охарактеризована и содержит в себе определенное ценностное ядро (Шпрангер, 2014).

Переживание чувства ЦСЖ - интенциональная, направленная активность. Это система аксиологических действий, которые могут иметь как экстериоризованную, так и интериоризованную форму. Их цель - укрепление и утверждение собственной бытийности (Диаб \& Кузнецов, 2019).

Предположение о механизме возникновения чувства ЦСЖ можно сделать, опираясь на идеи К.-Г. Юнга. Он писал о «ценностях элементов личности». Ценность исчисляется количеством психической энергии, вкладываемой в тот или иной элемент личности (Юнг, 2010). Ценность идеи означает, что она важна для регуляции поведения. Когда речь идет о ЦСЖ, объектом «вложения» психической энергии человека становится когнитивный образ (идея) всей его жизни в целом - ее зарождения, стадий, достижения кульминации, заката, ее особой миссии, критериев продуктивности и смысла.

По мнению А. Лэнгле, человек, переживающий дефицит чувства ЦСЯ , «болен бытием»; оно у него «опустошенное». Он может даже попытаться расстаться со своим бытием (попытка самоубийства у суицидальной личности) (Лэнгле, 2019).

Чувство ЦСЖ изучалось также в контексте научной проблематики восприятия и переживания времени жизни (c) Kuznietsov Marat, Diab Nabil

DOI (article): https://doi.org/10.32626/2227-6246.2020-48.175-205 http://journals.uran.ua/index.php/2227-6246 
и отношения к смерти. Восприятие времени своей жизни как чего-то бесконечного и не имеющего пределов спасает от страха смерти и способствует его вытеснению. Однако «расплатой» за этот защитный маневр является утрата чувства ЦСЖ (Зимбардо \& Бойд, 2010).

По мнению Р. Мэя, чувство ЦСЖ невозможно пережить, не переживая свободу. Условием обретения свободы является налаживание контакта с собственной судьбой, какой бы она ни была, безоговорочное ее принятие (Мэй, 2013).

Развитие чувства ЦСЖ - важная, связанная с когнитивным развитием линия становления личности в студенческом возрасте. Необходимость решения задач развития в эти годы, а также трудности, связанные с учебно-профессиональной деятельностью студентов, стимулируют развитие ЦСЖ. Они же при определенных условиях могут стать и препятствием для такого развития. Поэтому актуальным является эмпирическое исследование когнитивных предикторов развития чувства ЦСЖ у студентов.

Современная психология предлагает широкий спектр понятий, отражающих роль когнитивных процессов в переживании разнообразных чувств человека. Это и каузальные атрибуции (Weiner, 1985), и самоэффективность (Бандура, 2000), и атрибутивный стиль (Seligman \& Shulman, 1986), и имплицитные теории интеллекта и личности (Dweck \& Leggett, 1988), и воспринимаемый контроль (Skinner, Wellborn \& Connell, 1990), и др. Особое место в ряду этих категорий занимает понятие базисных убеждений - сформировавшихся у личности особых глубинных представлений о себе самой, об окружающем мире и о человеке вообще (Падун \& Котельникова, 2012; Janoff-Bulman, 1992). Базисные убеждения структурированы и организованы в систему. Они встроены в Образ Мира, составляют его основную, наиболее фундаментальную часть (Леонтьев, 1983). Получение каждой новой «порции» информации и ассимиляция ее в системе жизненного опыта опосредованы базисными

(c) Kuznietsov Marat, Diab Nabil DOI (article): https://doi.org/10.32626/2227-6246.2020-48.175-205 
убеждениями субъекта. Трудности и даже невозможность ассимиляции разных видов травматического опыта (например, боевого, опыта насилия и т. п.) обусловлены противодействием со стороны глубинных базисных убеждений субъекта (Виртц, 2014; Герман, 2015; Колесніченко, 2018; Магомед-Эминов, 1998; Тарабрина, 2009). Они же (базисные убеждения) при определенных условиях могут существенно смягчить негативное воздействие стрессоров и облегчить эффективное совладание с ними (Кадыров, 2012; Г. Кристал \& Дж. Кристал, 2006; Малкина-Пых, 2005).

Система базисных убеждений - это «...имплицитные, глобальные, устойчивые представления индивида о мире и о себе, оказывающие влияние на мышление, эмоциональные состояния и поведение человека» (Падун \& Котельникова, 2012: 28). Порождаемая сознанием человека картина реальности благодаря базисным убеждениям предстает как «assumptive world» («мир допущений») (Beder, 2004). Базисные убеждения участвуют в процессе фильтрации поступающей человеку информации. Тем самым они участвуют в структурировании и организации опыта, моделировании психических состояний и программировании действий.

Цель статьи - проверить предположение о том, что базисные убеждения сказываются на переживании чувства ЦСЖ у студентов. Эмпирическая проверка этого предположения необходима, так как базисные убеждения концентрируют в себе эмоционально значимую информацию о собственной жизни в целом. Тем самым они мотивируют принятие принципиальных решений в жизни и выбор линии поведения на высокообобщенных уровнях смысловой регуляции личности.

\section{Задачи статьи}

1. Изучить взаимосвязи показателей пяти компонентов структуры базисных убеждений, выделенных в когнитивистской концепции Р. Янофф-Бульмана (Janoff-Bulman, 1992) (c) Kuznietsov Marat, Diab Nabil

DOI (article): https://doi.org/10.32626/2227-6246.2020-48.175-205 http://journals.uran.ua/index.php/2227-6246 
с показателями источников переживания чувства ЦСЖ у студентов (эти источники эмпирически выявлены в наших предыдущих исследованиях) (Диаб \& Кузнецов, 2019; Кузнецов \& Диаб, 2020).

2. Выявить специфику корреляционных взаимосвязей в младшей и старшей группах студентов.

3. Определить когнитивные предикторы двух основных модусов переживания чувства ЦСЖ у студентов (модуса «сближения» с другими людьми и модуса «дистанцирования» от людей).

4. Построить регрессионную модель, предсказывающую шанс преобладания модуса «сближения» над модусом «дистанцирования» при переживании чувства ЦСЖ у студентов.

\section{Методы и методики исследования}

Для решения задач исследования была использована Шкала базисных убеждений Р. Янофф-Бульмана; в модификации М. А. Падун и А. В. Котельниковой (Падун \& Котельникова, 2012). У всех испытуемых фиксировались пять показателей: 1) убеждение о доброжелательности / враждебности окружающего мира (убеждения индивида относительно возможности безопасно доверять окружающему миру); 2) убеждение о справедливости окружающего мира (убеждение в том, что «каждый получает то, что заслуживает», т. е. вера индивида в справедливое распределение хороших и плохих событий между людьми); 3) убеждение о контроле (убеждение человека в том, что он контролирует происходящее с ним); 4) убеждение о иенности и значимости собственного «Я» (образ «Я» - убеждение индивида в том, что он достоин уважения и любви, что «он - хороший»); 5) убеждение об удаче (убеждение в том, что он в целом - «человек везучий»).

Для диагностики источников чувства ЦСЖ у студентов использован разработанный нами опросник (Диаб \& Кузнецов, 2019). Фиксировались показатели: 1) «Власть, статус,

(C) Kuznietsov Marat, Diab Nabil

DOI (article): https://doi.org/10.32626/2227-6246.2020-48.175-205 
богатство» (привязка чувства ЦСЗ к обладанию властью над другими людьми, высокому социальному статусу в обществе, обладанию большими материальными ресурсами); 2) «Oптилизл» (восприятие ЦСЖ сквозь призму приподнятого настроения, веры в благоприятный исход жизненных событий); 3) «Здоровье» (трактовка переживания чувства ЦСЖ как постоянного выполнения системы оздоровляющих практик, склонность придерживаться принципов здорового образа жизни); 4) «Салоконтроль, инфорлация, салоразвитие» (понимание ЦСЖ как компетентности в вопросах получения, интерпретации и эффективного использования внешней и внутренней информации для успешной деятельности); 5) «Близкие отношения, селья, востребованность» (акцент в понимании чувства ЦСЖ как наличия близких отношений со значимыми людьми); 6) «Дистанцирование от людей» (способность уединиться, переносимость и высокая оценка одиночества, пребывания наедине с самим собой). Каждый из источников чувства ЦСЖ отражает подкрепленную убеждениями готовность человека вести определенный образ жизни, ставить перед собой конкретные цели, ценить в своей жизни одни ее аспекты и игнорировать другие.

В исследовании участвовали 286 студентов (247 женщин и 39 мужчин) Харьковского национального педагогического университета имени Г. С. Сковороды, в основном психологи, в возрасте от 17 до 46 лет. Для обработки данных использовался пакет программ IBM SPSS Statistics 22.

Показатели источников чувства ЦСЖ для всей выборки испытуемых подвергались кластерному анализу методом $k$-means ( $k$-средних). Все испытуемые были разделены на две группы. Основание для такого разделения - проявление двух основных интегральных метасмыслов (модусов), которые содержатся в понимании и переживании чувства ЦСЖ. Один из этих интегральных смыслов реализуется в идее движения навстречу людям («Ценность сближения»), а другой - в идее удаления от них («Ценность дистанциро(c) Kuznietsov Marat, Diab Nabil

DOI (article): https://doi.org/10.32626/2227-6246.2020-48.175-205 
DOI: https://doi.org/10.32626/2227-6246.2020-48 2020. ВИПУСК 48

вания»). Группы «Дистанцирования» и «Сближения» значительно различаются по всем шести показателям источников чувства ЦСЖ. По первым пяти показателям группа «Сближения» значительно превосходит группу «Дистанцирования», а по шестому - заметно уступает (рис. 1). Математико-статистическое обоснование корректности результатов кластеризации содержится в (Кузнецов \& Диаб, 2020).

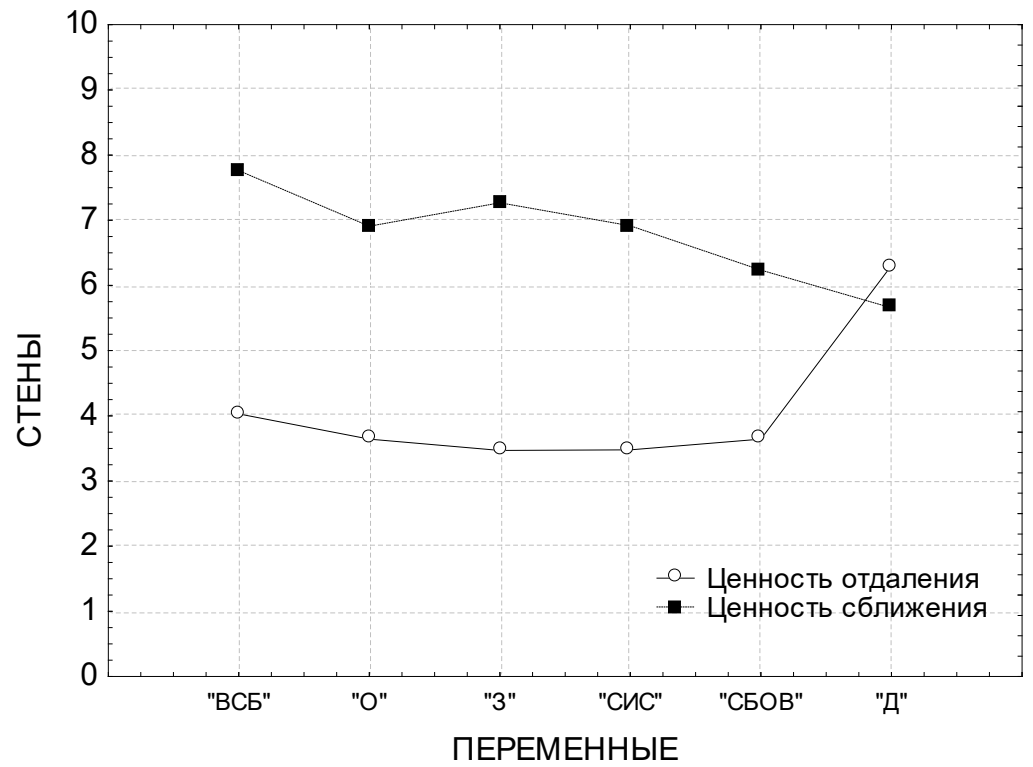

Puc. 1. Кластерные профили проявления двух типов ЦСふ - ценности сближения и ценности отдаления

Прилечание: «ВСБ» - «Власть, статус богатство»; «О»- «Оптимизм»; «З» - «Здоровье»; «СИС» - «Самоконтроль, информация, саморазвитие»; «СБОВ» - «Семья, близкие отношения, востребованность»; «Д» - «Дистанцирование» .

При обработке результатов использовались расчеты коэффициентов линейной корреляции $\left(\mathrm{r}_{\mathrm{xy}}\right)$ по К. Пирсону и алгоритм логистической регрессии.

(C) Kuznietsov Marat, Diab Nabil

DOI (article): https://doi.org/10.32626/2227-6246.2020-48.175-205 
ISSN 2227-6246 (Print)

ISSN 2663-6956 (Online)

ПРОБЛЕМИ СУЧАСНӦ̈ ПСИХОЛОГІЇ

DOI: https://doi.org/10.32626/2227-6246.2020-48

2020. ВИПУСК 48

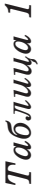

空

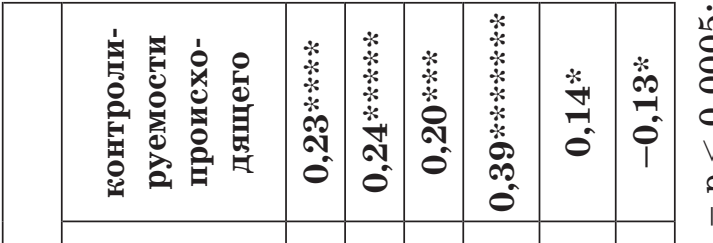

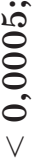

er

茴

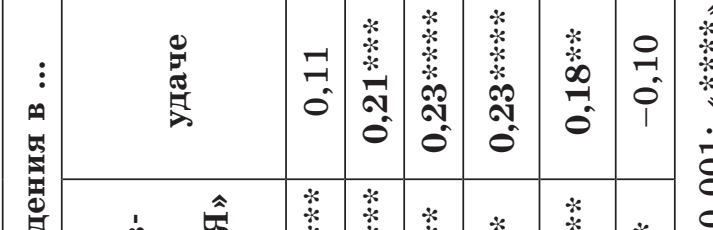

¿ั

○ $\Xi$

我

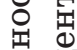

要点

兒

苗

艺

要

战

啨

D

$\stackrel{x}{*}$

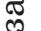

त.

帘

ชิ

㱐

D

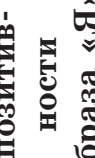

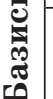

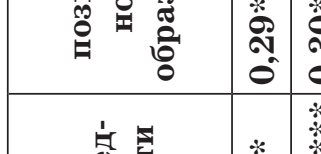

它署

产

*

获

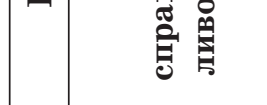

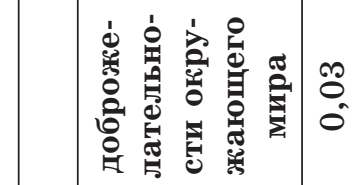

\begin{tabular}{|c|c|c|c|c|c|c|c|}
\hline 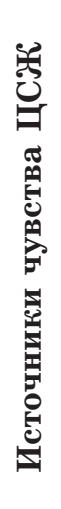 & 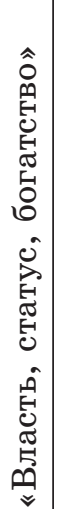 & 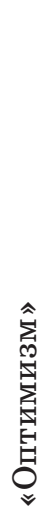 & 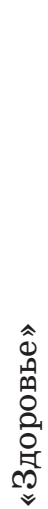 & 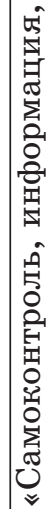 & 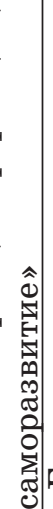 & 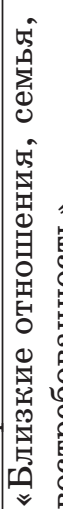 & 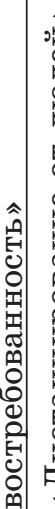 \\
\hline
\end{tabular}

$\begin{array}{ll}\cdots & 0 \\ 1 & 0 \\ 0 & 0 \\ 0 & 0 \\ 0 & 0 \\ 0 & 0\end{array}$

e. 2

|

0
0
0
8

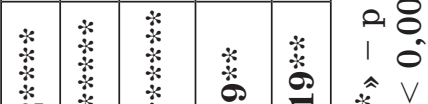

ஸู

$* 2$

îे

0

V

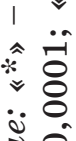

$\frac{2}{4} \mathrm{~V}$

选

है

를

茫

(C) Kuznietsov Marat, Diab Nabil

DOI (article): https://doi.org/10.32626/2227-6246.2020-48.175-205

http://journals.uran.ua/index.php/2227-6246 


\section{Результаты и дискуссии}

В табл. 1 представлены коэффициенты корреляции показателей источников чувства ЦСЖ и базисных убеждений, вычисленные во всей выборке студентов.

Обнаружены тесные и очень тесные позитивные корреляции четырех шкал опросника ЦСК со всеми без исключения показателями Шкалы базисных убеждений.

Речь идет, прежде всего, о таких основаниях для переживания чувства ЦСЖ, как «Оптимизм» (диапазон коэффициентов корреляции варьирует от $\mathrm{r}_{\mathrm{xy}}=0,21$ до $\mathrm{r}_{\mathrm{xy}}=0,30$ при уровнях значимости от $\mathrm{p}<0,001$ до $\mathrm{p}<0,00001)$, «Здоровье» (от $\mathrm{r}_{\mathrm{xy}}=0,20$ до $\mathrm{r}_{\mathrm{xy}}=0,27$ при уровнях значимости от $\mathrm{p}<0,001$ до $\mathrm{p}<0,00005)$, «Самоконтроль, информация и саморазвитие» (от $\mathrm{r}_{\mathrm{xy}}=0,22$ до $\mathrm{r}_{\mathrm{xy}}=0,39$ при уровнях значимости от $\mathrm{p}<0,0005$ до $\mathrm{p}<0,00001)$, «Близкие отношения, семья, востребованность» (от $\mathrm{r}_{\mathrm{xy}}=0,14$ до $\mathrm{r}_{\mathrm{xy}}=0,27$ при уровнях значимости от $\mathrm{p}<0,05$ до $\mathrm{p}<0,00005)$. Все пять видов базисных убеждений, выделенных Р. Янофф-Бульманом, оказались важными для того, чтобы студенты связывали ЦСЖК: 1) с оптимизмом (верой в благоприятное развитие событий), 2) со здоровьем (как способностью поддерживать субъективное благополучие) и 3) самоконтролем, получением информации, саморазвитием. При этом, придерживаться правила «Ценить свою жизнь - это значит неслотря ни на что оставаться оптилистол» в наибольшей степени свойственно студентам, которые убеждены в позитивности образа «Я». Студенты, для которых ЦСҢ - это признание, прежде всего, ценности здоровья (психологического, физического, социального, духовного) и борьбы за него, больше других убеждены в справедливости окружающего мира. Если студенты значительно опережали других испытуемых в силе своего убеждения в контролируемости происходящего, то они, как правило, находили основание для чувства ЦСЖ в развитии навыков самоконтроля, получении и использовании информации, усовершенствовании собственной

(C) Kuznietsov Marat, Diab Nabil DOI (article): https://doi.org/10.32626/2227-6246.2020-48.175-205 
личности. Вероятность того, что, говоря о ЦСЖ, студенты будут отмечать важность семьи, близких отношений и своей нужности другим людям, наиболее стремительно повышается при выраженных базисных убеждениях в справедливости окружающего мира и позитивности образа своего «Я».

Вероятность трактовки студентами ЦСЖ как обладания властью над другими людьми, значительными материальными и финансовыми ресурсами, высоким социальным статусом также повышается при акцентуированности базисных убеждений. Но не всех, а только некоторых. Правило «По-настоящелу иенна только та жизнь, когда ты обладаешь большой властью, богатствол и высокил статусол" действует в основном для тех, кто убежден в позитивности образа своего «Я» $\left(\mathrm{r}_{\mathrm{xy}}=0,29 ; \mathrm{p}<0,00001\right)$ и в контролируемости происходящего $\left(\mathrm{r}_{\mathrm{xy}}=0,23 ; \mathrm{p}<0,0005\right)$. В меньшей степени (но все-таки на уровне статистической значимости) проявляется базисное убеждение в справедливости $\left(\mathrm{r}_{\mathrm{xy}}=0,17 ; \mathrm{p}<0,005\right)$.

Коэффициенты корреляции, полученные в группе студентов, для которых ЦСЖ заключается в возможности уединиться, отдалиться от других людей, как можно чаще быть предоставленными самим себе, сильно отличаются от корреляций, которые выявлены в остальных группах студентов. Эти корреляции, во-первых, отрицательны, во-вторых, не тотальны и, в-третьих, не столь тесные, как в других группах испытуемых. Склонные отдаляться от других студенты имеют опыт неудач в вопросах контроля над происходящими процессами, а также аккумулируют негативную информацию о самих себе. Эти студенты отнюдь не уверены в том, что окружающий мир настроен по отношению к ним доброжелательно $\left(\mathrm{r}_{\mathrm{xy}}=-0,19 ; \mathrm{p}<0,005\right)$. В их образе «Я» акцентированы негативные черты $\left(\mathrm{r}_{\mathrm{xy}}=-0,19 ; \mathrm{p}<0,005\right)$. Кроме того, такие студенты сомневаются в своей способности контролировать процессы, происходящие в их жизни $\left(\mathrm{r}_{\mathrm{xy}}=-0,13 ; \mathrm{p}<0,05\right)$. Интенсивные контакты с другими (c) Kuznietsov Marat, Diab Nabil

DOI (article): https://doi.org/10.32626/2227-6246.2020-48.175-205 
людыми и включенность в групповые процессы, по-видимому, подтверждают соответствующую интерпретацию социальной реальности. Эта интерпретация болезненна, поэтому дистанцирующиеся студенты предпочитают одиночество, неучастие, а также формы активности, не требующие открытости и частых контактов с окружающими. У них постепенно складывается когнитивно-регуляторный паттерн, получивший название «прототип одинокой личности» (Хоровиц, Френч \& Андерсон, 1989). Складывается система характерологических черт, установок и аргументаций в защиту дистанцированного и закрытого образа жизни, а на уровне ценностной сферы формируется соответствующий смысловой комплекс. Развивается соответствующий индивидуальный коммуникативный стиль, своеобразная манера поведения в случае, если приходится (например, в силу производственной необходимости или из-за участия в совместной учебной деятельности) находиться среди людей.

Интересно (и, по-видимому, не случайно) то, что триада базисных убеждений, выявленная нами у студентов с «Дистанцирующимся» вариантом переживания чувства ЦСЖ ( «Недоброжелательность Мира ко мне» - «Негативный образ «Я» - «Неконтролируемость происходящего»), напоминает (по крайней мере, в первых двух компонентах) знаменитую Депрессивную Триаду А. Бека ( Мир плохой», «Я плохой», «Будущего нет») (Бек, Раш, Шо \& Эмери, 2003). Она также согласуется с основными результатами исследования когнитивных оснований оптимизма и пессимизма в концепции М. Селигмана (Селигман, 2015).

Механизмы категоризации жизненных событий развиваются с возрастом. Базисные убеждения, в основном отличаясь постоянством и консервативностью, тем не менее, корректируются, дифференцируются и постепенно трансформируются сообразно накопленному жизненному опыту (Лактионов, 2010; Flavell, 1992). Поэтому специально pacсматривались корреляции показателей опросников ЦСЖ и

(C) Kuznietsov Marat, Diab Nabil DOI (article): https://doi.org/10.32626/2227-6246.2020-48.175-205 
DOI: https://doi.org/10.32626/2227-6246.2020-48

базисных убеждений отдельно в младшей $(\mathrm{n}=177$; возраст от 17 до 20 лет; $\mathrm{m}=19,06 \pm 1,02$ года) и в старшей ( $\mathrm{n}=109$; возраст - от 21 до 46 лет; $\mathrm{m}=26,76 \pm 6,40$ года) группах студентов. Коррелограммы на рис. 2 и 3 отражают системы взаимосвязей между показателями основных источников чувства ЦСЖ и показателями базисных убеждений у студентов младшей и старшей групп соответственно. Студенты младшей и старшей групп продемонстрировали определенное сходство в структуре взаимосвязей показателей базисных убеждений и параметров переживания чувства ЦСЖ.

Как у старших, так и у младших студентов базисные убеждения одинаковым образом участвуют в таком осмыслении ЦСЖ, как обеспечение и поддержание «Оптилизла». Это же можно сказать об активности «Салоконтроля», поиске «Инфорлации», обеспечении «Салоразвития».

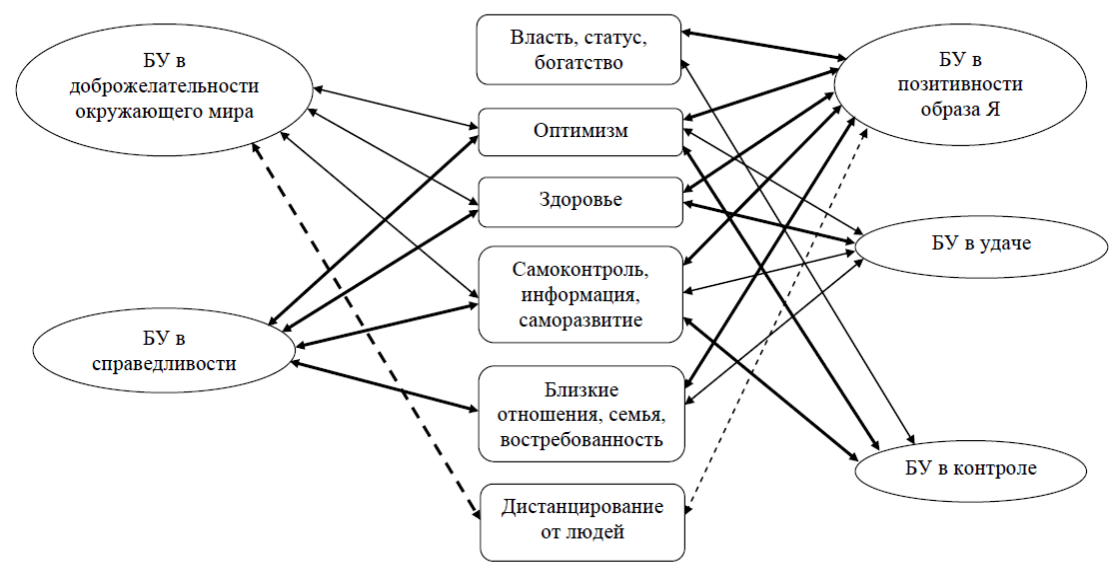

Puc. 2. Структура взаимосвязей между показателями источников чувства ЦСЖ и показателями базисных убеждений в младшей группе студентов

Прилечание:

$-\mathrm{p}<0,05$

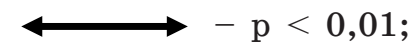

$\longleftrightarrow-$ позитивные корреляции; $4----\rightarrow-$ негативные корреляции; БУ - базисные убеждения.

(C) Kuznietsov Marat, Diab Nabil

DOI (article): https://doi.org/10.32626/2227-6246.2020-48.175-205 


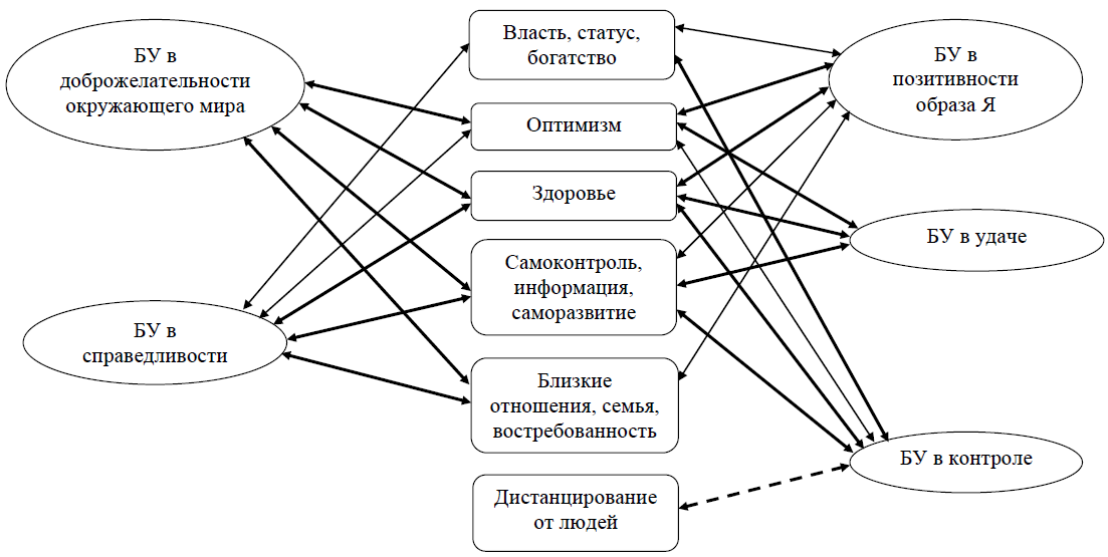

Puc. 3. Структура взаимосвязей между показателями источников чувства ЦСЖ и показателями базисных убеждений в старшей группе студентов

Прилечание: $\longleftrightarrow-\mathrm{p}<0,05 ; \longleftrightarrow-\mathrm{p}<0,01$; $\longleftrightarrow-$ позитивные корреляции; $\longrightarrow-----\rightarrow$ негативные корреляции; БУ - базисные убеждения.

Относительно остальных групп смыслов, вкладываемых в переживание ЦСЖ, выявлены определенные возрастные различия.

Во-первых, для переживания чувства ЦСЖ как обретения Власти, Статуса и Богатства как для младших, так и для старших важны базисные убеждения в позитивности образа «Я» и в контроле за происходящим. Однако в сознании студентов старшего возраста отчетливо проявляется роль базисного убеждения в справедливости. Этот результат соответствует основным закономерностям, которые выявил Д. Макклелланд при изучении того, как зрелость влияет на проявление мотива власти (Макклелланд, 2007). Этот автор выделил и эмпирически подтвердил существование четырех стадий развития мотива власти с возрастом. По мере взросления меняется «модальность» мотива власти, становясь все

(C) Kuznietsov Marat, Diab Nabil DOI (article): https://doi.org/10.32626/2227-6246.2020-48.175-205 
DOI: https://doi.org/10.32626/2227-6246.2020-48

более зрелой и учитывающей мнение, интересы и чаяния других людей и организаций.

Во-вторых, для проявления чувства ЦСЖ по типу борьбы за Здоровье у студентов старшей группы, в отличие от младших, акцентирована роль базисного убеждения в контроле над происходящим. Тем самым подтверждается ранее установленный факт, что молодыми наличие здоровья воспринимается как «само собой разумеющееся», присутствующее «по умолчанию». У более зрелых людей обладание здоровьем превращается в «награду, которую надо заслужить» кропотливой и целенаправленной работой над собой, применением саногенных и оздоровляющих практик (Кузнецов \& Зотова, 2017).

В-третьих, условиями переживания чувства ЦСЖ как установления Близких отношений, создания Сельи и обеспечения социальной Востребованности для обеих групп испытуемых являются базисные убеждения в позитивном образе «Я» и в справедливости окружающего мира. Однако для студентов младшей группы необходимо также базисное убеждение в удаче, а для старших - в доброжелательности окружающего мира. Удача - результат случайности, которая почти не зависит от собственных усилий субъекта. Доброжелательность окружающих - ответ на доброжелательную линию поведения, которую сформировал и активно проводит сам субъект, неся за нее личную ответственность.

В-четвертых, переживание чувства ЦСЖ как дистанцирования от других имеет более глубокие когнитивно-эмоциональные «корни» в личности студентов младшей группы. $\mathfrak{K}$ такому варианту переживания склонны студенты, которые не убеждены в доброжелательности окружающего мира и сомневаются в позитивности образа «Я». У студентов старшей возрастной группы стремление дистанцироваться коррелирует с сомнениями в контролируемости происходящего.

(C) Kuznietsov Marat, Diab Nabil

DOI (article): https://doi.org/10.32626/2227-6246.2020-48.175-205 
Поскольку корреляционный анализ не позволяет устанавливать причинно-следственные связи, все эмпирические данные были подвергнуты регрессионному анализу. Для уточнения информации о когнитивных предикторах чувства ЦСЖ у студентов использовалась логистическая регрессия. Это один из вариантов множественной регрессии, в котором в качестве зависимой используется дихотомическая, категориальная переменная (Наследов, 2013). В качестве зависимой переменной выступила тенденция сближаться с людьми или, наоборот, дистанцироваться от них при актуализации чувства ЦСЖ⿱. Дихотомическая зависимая переменная в данном виде регрессионного анализа применяется как показатель принадлежности / непринадлежности испытуемого к группе «Сближающихся с другими людьми» или, наоборот, «Дистанцирующихся». В нашем исследовании - это два специфических модуса, две противоположные смысловые направленности переживания ЦСЖ⿱

Выявлялся шанс преобладания одной из тенденций над другой в зависимости от показателей выраженности базисных убеждений личности студентов. При построении регрессионного уравнения был использован метод пошагового включения предикторов, оказывающих наибольшее воздействие на зависимую переменную. Шаги прекращались, когда в уравнение включался последний значимый предиктор. Понадобилось три шага для того, чтобы включить все переменные в регрессионную модель.

В табл. 2 представлены значения статистики, которая отражает факт влияния на зависимую переменную всех предикторов заданной модели, блока, шага.

На шаге 1 все три критерия $\chi^{2}$ равны. Включение второй и третьей переменной на 2-м и особенно на 3-м шаге значительно улучшает регрессионную модель, о чем свидетельствует увеличение значения критерия $\chi^{2}$.

(C) Kuznietsov Marat, Diab Nabil

DOI (article): https://doi.org/10.32626/2227-6246.2020-48.175-205 
Универсальные критерии коэффициентов регрессионной модели

\begin{tabular}{|c|l|c|c|c|}
\hline Шаги & \multicolumn{1}{|c|}{ Критерии } & $\chi^{2}$ & Ст. св. & $\mathbf{p}$ \\
\hline \multirow{3}{*}{1} & Шаг & 30,894 & 1 & 0,000 \\
\cline { 2 - 5 } & Блок & 30,894 & 1 & 0,000 \\
\cline { 2 - 5 } & Модель & 30,894 & 1 & 0,000 \\
\hline \multirow{3}{*}{2} & Шаг & 13,633 & 1 & 0,000 \\
\cline { 2 - 5 } & Блок & 44,527 & 2 & 0,000 \\
\cline { 2 - 5 } & Модель & 44,527 & 2 & 0,000 \\
\hline \multirow{3}{*}{3} & Шаг & 4,180 & 1 & 0,041 \\
\cline { 2 - 5 } & Блок & 48,708 & 3 & 0,000 \\
\cline { 2 - 5 } & Модель & 48,708 & 3 & 0,000 \\
\hline
\end{tabular}

таблица 3

Классификационная таблица: эмпирически наблюдаемые и прогнозируемые значения независимой переменной

\begin{tabular}{|c|c|c|c|c|}
\hline \multirow{3}{*}{ 疍 } & \multicolumn{3}{|c|}{ Значения зависимой переменной } & \multirow{3}{*}{$\begin{array}{c}\% \text { коррект- } \\
\text { ных }\end{array}$} \\
\hline & \multirow[b]{2}{*}{ Наблюдаемые } & \multicolumn{2}{|c|}{ Предсказанные } & \\
\hline & & $\begin{array}{c}\text { «Дистанци- } \\
\text { рование» }\end{array}$ & $\begin{array}{l}\text { «Сбли- } \\
\text { жение» }\end{array}$ & \\
\hline \multirow{3}{*}{1} & «Дистанцирование» & 85 & 49 & 63,4 \\
\hline & «Сближение» & 54 & 98 & 64,5 \\
\hline & Общая процентная доля & & & 64,0 \\
\hline \multirow{3}{*}{2} & «Дистанцирование» & 84 & 50 & 62,7 \\
\hline & «Сближение» & 38 & 114 & 75,0 \\
\hline & Общая процентная доля & & & 69,2 \\
\hline \multirow{3}{*}{3} & «Дистанцирование» & 82 & 52 & 61,2 \\
\hline & «Сближение» & 35 & 117 & 77,0 \\
\hline & Общая процентная доля & & & 69,6 \\
\hline
\end{tabular}

Прилечание: разделяющее значение $=0,500$.

(C) Kuznietsov Marat, Diab Nabil

DOI (article): https://doi.org/10.32626/2227-6246.2020-48.175-205 
DOI: https://doi.org/10.32626/2227-6246.2020-48 2020. ВипУСК 48

Классификационная таблица 3 отражает результаты сравнения прогнозируемых значений зависимой переменной, которые можно рассчитать на основе регрессионного уравнения, и фактически наблюдаемых значений. Число корректных случаев дифференциации испытуемых, проявляющих тенденцию к «Сближению» или «Дистанцированию» при переживании чувства ЦСЖ, после третьего шага приближается к 69,6\% .

Постепенное включение независимых переменных в регрессионное уравнение, а также статистические эффекты такого включения на каждом шаге иллюстрируют данные табл. 4.

Таблица 4

Эффекты включения переменных в регрессионное уравнение на каждом шаге его построения

\begin{tabular}{|c|c|c|c|c|c|c|c|}
\hline 葛 & Переменные & B & $\begin{array}{l}\text { Стд. } \\
\text { ош. }\end{array}$ & Вальд & $\begin{array}{l}\text { Ст. } \\
\text { св. }\end{array}$ & $\mathbf{p}$ & $\begin{array}{l}\text { Exp } \\
\text { (B) }\end{array}$ \\
\hline \multirow{2}{*}{$1^{\mathrm{a}}$} & БУ: справедливость & 0,296 & 0,057 & 27,174 & 1 & 0,000 & 1,344 \\
\hline & Константа & $-1,512$ & 0,336 & 20,283 & 1 & 0,000 & 0,220 \\
\hline \multirow{3}{*}{$2^{\mathrm{b}}$} & БУ: справедливость & 0,245 & 0,059 & 17,445 & 1 & 0,000 & 1,278 \\
\hline & БУ: контроль & 0,243 & 0,068 & 12,842 & 1 & 0,000 & 1,275 \\
\hline & Константа & $-2,913$ & 0,534 & 29,702 & 1 & 0,000 & 0,054 \\
\hline \multirow{4}{*}{$3^{c}$} & БУ: справедливость & 0,208 & 0,061 & 11,444 & 1 & 0,001 & 1,231 \\
\hline & БУ: образ «Я» & 0,118 & 0,058 & 4,111 & 1 & 0,043 & 1,125 \\
\hline & БУ: контроль & 0,200 & 0,071 & 7,876 & 1 & 0,005 & 1,221 \\
\hline & Константа & $-3,295$ & 0,577 & 32,624 & 1 & 0,000 & 0,037 \\
\hline
\end{tabular}

Примечание: «БУ» - базисное убеждение; а - переменные, введенные на шаге 1 «БУ: справедливость»; b - переменные, введенные на шаге 2 «БУ: контроль»; с - переменные, введенные на шаге 3 «БУ: образ «Я».

(C) Kuznietsov Marat, Diab Nabil DOI (article): https://doi.org/10.32626/2227-6246.2020-48.175-205 
Данные табл. 4 дают возможность оценить степень влиятельности каждого предиктора по отдельности, а также определить степень значимости константы (свободного члена регрессионного уравнения). Так, на третьем шаге наиболее высокий В-коэффициент выявлен по отношению к такой независимой переменной, как «Базисное убеждение в справедливости» $(\mathrm{B}=0,208 ; \mathrm{p}<0,001)$. Именно по отношению к этой переменной оказалась наиболее высокой статистика Вальда $(11,444)$. Следовательно, переживание чувства ЦСЖ как активности, сближающей человека с другими людьми, детерминировано у студентов, прежде всего, убеждением в том, что отношения строятся на принципе справедливости.

Вторым по влиятельности предиктором, повышающим шанс преобладания сближения над дистанцированием при переживании чувства ЦСЖ у наших испытуемых, оказалась такая когнитивная структура сознания, как базисное убеждение в контроле $(\mathrm{B}=0,200 ; \mathrm{p}<0,005 ;$ критерий Вальда $=7,876)$. Контроль над происходящим информирует субъекта о границах его возможностей, укрепляет эго, способствует четкой дифференциации процессов, на которые субъект может влиять, и процессов, на которые повлиять невозможно (по крайней мере, в данный момент) (Olefir, Kuznetsov \& Plokhikh, 2019). С точки зрения Р. Мэя, последнее чрезвычайно важно для обретения подлинной свободы, так как способствует «принятию неизбежного», «встрече человека с собственной судьбой». После такой встречи ЦСЖ становится для человека неоспоримой (Мэй, 2012). Контроль способствует преодолению элементов выученной беспомощности (Seligman \& Maier, 1967), повышает жизненный тонус человека и препятствует возникновению депрессии, лежит в основе укрепления жизнеутверждающих оптимистических установок личности (Селигман, 2015). Через контроль человек поддерживает свою психологическую суверенность (суверенность физического тела, своей территории, личных вещей, временного режима и привычек, социальных связей, (c) Kuznietsov Marat, Diab Nabil

DOI (article): https://doi.org/10.32626/2227-6246.2020-48.175-205 
вкусов и ценностей). Это - залог успешного автономного поведения, аутентичности собственного бытия (Нартова-Бочавер, 2008).

Базовое убеждение в позитивности образа «Я» - еще один статистически значимый предиктор переживания ЦСЖ как сближения с другими людьми у студентов $(\mathrm{B}=0,118$; $\mathrm{p}<0,04$; критерий Вальда $=4,111)$. Эти данные определенным образом согласуются с тезисом Э. Фромма о том, что приязнь к себе (способность любить и ценить себя) является важной предпосылкой чувства любви, обращенного вовне, т. е. связывающего человека с другими людьми (Фромм, 1992). Статистической значимостью обладает также и константа (свободный член) регрессионного уравнения. Оно имеет такой вид:

$\ln \left[\frac{\text { Рсближ. }}{\text { Рдистани. }}\right]=-3,295+$ 0,208БУСправедл. + 0,2БУКонтр. + 0,118БУОбр.Я,

где $\mathrm{P}_{\text {сближ. }}$ - вероятность актуализации идеи сближения с другими людьми у испытуемого, переживающего чувство ЦСЖ; $\mathrm{P}_{\text {дистанц. }}$ - вероятность доминирования идеи дистанцирования от других у испытуемого, переживающего чувство ЦСЖ; $\mathrm{P}_{\text {сближ. }} / \mathrm{P}_{\text {дистанц. }}$ - шанс, с которым идея сближения с другими будет преобладать над идеей дистанцирования от других при переживании испытуемым чувства ЦСЖא; $\ln \left[\mathrm{P}_{\text {сближ. }} / \mathrm{P}_{\text {дистанц. }}\right]-$ логит, т. е. натуральный логарифм шанса; БУ ние в справедливости; БУ БУ

Влияние переменных базисного убеждения в доброжелательности окружающего мира и базисного убеждения в удаче на зависимую переменную (шанс преобладания тенденции сближения над тенденцией дистанцирования при актуализации чувства ЦСЖ у юношей и девушек) оказалось слабым и не достигло уровня статистической значимости. Прогностические возможности регрессионной модели оказались достаточно высокими: значение $\mathrm{R}^{2}$ Нэйджелкерка

(C) Kuznietsov Marat, Diab Nabil DOI (article): https://doi.org/10.32626/2227-6246.2020-48.175-205 
свидетельствует о том, что все предикторы модели в совокупности объясняют 51,9\% общей дисперсии зависимой переменной.

\section{Выводы и перспективы дальнейших исследований}

Когнитивные переменные (базисные убеждения) и показатели источников переживания чувства ЦСЖ у студентов взаимосвязаны. При этом стремление дистанцироваться с большинством показателей базисных убеждений связано отрицательно, а показатели остальных источников переживания ЦСЖ - положительно. Обнаружены возрастные особенности корреляции показателей чувства ЦСЖ с показателями базисных убеждений. В старшей группе студентов переживание чувства ЦСЖ как обладания властью, статусом и богатством теснее связано с базисным убеждением в справедливости, чем у студентов младшей группы. Переживая чувство ЦСЖ как обладание здоровьем, студенты старшей группы чаще, по сравнению с младшими студентами, отмечают важность контроля над событиями собственной жизни. Старшие студенты, в отличие от младших, в вопросах, касающихся семьи, близких отношений и социальной востребованности, значительно меньше уповают на удачу, нежели студенты младшей группы.

Независимо от возраста, преобладание тенденции сближения над тенденцией дистанцирования при переживании чувства ЦСЖ у студентов детерминировано тремя когнитивными предикторами. Убеждения в справедливости, в контролируемости происходящего, а также в позитивности образа «Я»- причина того, что студенты связывают переживание ЦСЖ со сближением с другими людьми. Убеждения в доброжелательности окружающего мира и в собственной удаче не вошли в систему когнитивных предикторов, которые обеспечивают повышение шанса преобладания модуса сближения с другими людьми над модусом дистанцирования при переживании чувства ЦСЖ у студентов.

C Kuznietsov Marat, Diab Nabil

DOI (article): https://doi.org/10.32626/2227-6246.2020-48.175-205 
Перспективой дальнейших исследований является изучение роли чувства ЦСК в генезисе одиночества, невротических стилей коммуникации и деятельности, депрессии и суицидов. В то же время, специальное изучение чувства ЦСЖ может стать одним из направлений развития так называемой «позитивной психологии», концентрирующейся на лучших сторонах человеческой жизни. Само понятие ЦСЖ может по праву войти в категориальный тезаурус позитивной психологии наряду с понятиями Счастья, Потока, Пик-переживаний, Самоэффективности, Оптимизма, Психологического и Духовного здоровья, Надежды и др.

\section{Литература}

Бандура А. Теория социального научения. Санкт-Петербург : Евразия, 2000. $320 \mathrm{c}$.

Бек А., Раш А., Шо Б., Эмери Г. Когнитивная терапия депрессии. Санкт-Петербург : Питер, 2003. 304 с.

Виртц У. Убийство души. Инцест и терапия. Москва : Когито-Центр, 2014. $293 \mathrm{c}$.

Герман Дж. Психологічна травма та шлях до видужання. Наслідки насильства: від знущань у сім'ї до політичного терору. Львів : «Вид-во Старого Лева», 2015. 416 c.

Джонсон Р., Руль Дж. Проживая свою непрожитую жизнь. Москва : Институт общегуманитарных исследований, 2017. 248 с.

Диаб Н., Кузнецов М. А. Структурные особенности чувства ценности собственной жизни у студентов. Вісник Харківського національного педагогічного університету імені Г. С. Сковороди. Психологія. Харків : ХНПУ, 2019. Вип. 60. С. 69-93. URL : https://doi.org/ 10.34142/23129387.2019.60.04.

Зимбардо Ф., Бойд Дж. Парадокс времени. Новая психология времени, которая улучшит вашу жизнь. Санкт-Петербург : Речь, 2010. $352 \mathrm{c.}$

Кадыров Р. В. Посттравматическое стрессовое расстройство (PTSD): состояние проблемы, психодиагностика и психологическая помощь. Санкт-Петербург : Речь, 2012. 448 с.

Колесніченко О. С. Засади бойової психологічної травматизації військовослужбовців Національної гвардії України: монографія. Харків : ФОП Бровін О. В., 2018. 488 с.

(C) Kuznietsov Marat, Diab Nabil

DOI (article): https://doi.org/10.32626/2227-6246.2020-48.175-205 
DOI: https://doi.org/10.32626/2227-6246.2020-48 2020. випУСК 48

Кристал Г., Кристал Дж. Интеграция и самоисцеление. Аффект, травма и алекситимия. Москва : Институт общегуманитарных исследований, 2006. 800 с.

Кузнецов М. А., Зотова Л. Н. ЖКизнестойкость и образ здоровья у студентов. Харьков : Изд-во «Диса Плюс», 2017. 397 с. URL : http:// dspace.hnpu.edu.ua/handle/123456789/2952.

Кузнецов М. А., Диаб Н. Темпоральные предикторы чувства ценности собственной жизни в юношеском возрасте. Eurasian Scientific Congress. The 1st International scientific and practical conference «Eurasian scientific congress» (January 27-28, 2020). Barcelona, Spain : Barca Academy Publishing, 2020. P. 473-478.

Лактионов А. Н. Координаты индивидуального опыта. Харьков : ХНУ имени В. Н. Каразина, 2010. 366 с.

Леонтьев А. Н. Образ мира. Избранные психологические произведения. В 2-х тт. Москва : Педагогика, 1983. Т. II. С. 251-261.

Лэнгле А. Воплощенная экзистенция. Развитие, применение и концепты экзистенциального анализа. Материалы для психотерапии, консультирования и коучинга. Харьков : Гуманитарный Центр, 2019. 462 с.

Магомед-Эминов М. Ш. Трансформация личности. Москва : Психоаналитическая Ассоциация, 1998. 496 с.

Макклелланд Д. Мотивация человека. Санкт-Петербург : Питер, 2007. 672 с.

Малкина-Пых И. Г. Экстремальные ситуации. Москва : Изд-во «Эксмо», 2005. 960 с.

Мэй Р. Свобода и судьба. Москва : Институт общегуманитарных исследований, 2012. 288 с.

Нартова-Бочавер С. К. Человек суверенный: психологическое исследование субъекта в его бытии. Санкт-Петербург : Питер, 2008. 400 с.

Наследов А. Д. IBM SPSS Statistics 20 и AMOS: профессиональный статистический анализ данных. Санкт-Петербург : Питер, 2013. 416 с.

Падун М. А., Котельникова А. В. Психическая травма и картина мира: теория, эмпирия, практика. Москва : Изд-во «Институт психологии РАН», 2012. 206 с.

Селигман М. Как научиться оптимизму: измените взгляд на мир и свою жизнь. Москва : Альпина Паблишер, 2015. 338 с.

Тарабрина Н. В. Психология посттравматического стресса: теория и практика. Москва : Изд-во «Институт психологии РАН», 2009. 304 c.

Фромм Э. Искусство любить. Душа человека. Москва : Республика, 1992. C. 109-178.

(C) Kuznietsov Marat, Diab Nabil

DOI (article): https://doi.org/10.32626/2227-6246.2020-48.175-205 http://journals.uran.ua/index.php/2227-6246 
Хоровиц Л. М., Френч Р. С., Андерсон К. А. Прототип одинокой личности. Лабиринты одиночества. Москва : Прогресс, 1989. С. 243274.

Шпрангер Э. Формы жизни: Гуманитарная психология и этика личности. Москва : «Канон ${ }^{+}$; РООИ «Реабилитация», 2014. 400 с.

Юнг К.-Г. Об энергетике души. Москва : Академический проект; Фонд «Мир», 2010. 297 с.

Beder, J. (2004). Loss of the assumptive world - How we deal with death and loss. Omega, 50 (4), 255-265. URL : https://doi.org/10.2190/ GXH6-8VY6-BQ0R-GC04..

Dweck, C. S., \& Leggett, E. L. (1988). A Social-Cognitive Approach to Motivation and Personality. Psychological Review, 95 (2), 256-273. URL : http://dx.doi.org/10.1037/0033-295X.95.2.256.

Flavell, J. H. (1992). Cognitive Development: Past, Present, and Future. Developmental Psychology, 28 (6), 998-1005.

Janoff-Bulman, R. (1992). Shattered assumptions: Toward a new psychology of trauma. New York : Free Press. URL : https://doi.org/ 10.1080/00029157.1994.10403078.

Olefir, V., Kuznetsov, M., \& Plokhikh, V. (2019). Effect of physical exercises and perceived stress interaction on students' satisfaction with life. Pedagogics, Psychology, Medical-Biological Problems of Physical Training and Sports, 23 (1), 30-35. URL : https://doi.org/ 10.15561/18189172.2019.0105.

Seligman, M. E., \& Maier, S. F. (1967). Failure to escape traumatic shock. Journal of Experimental Psychology, 74 (1), 1-9. URL : https://doi. org/10.1037/h0024514.

Seligman, M. E. P., \& Shulman, P. (1986). Explanatory style as a predictor of productivity and quitting among life insurance sales agents. Journal of Personality and Social Psychology, 50, 832-838.

Skinner, E. A., Wellborn, J. G., \& Connell, J. P. (1990). What it takes to do well in school and whether I've got it: The role of perceived control in children's engagement and school achievement. Journal of Educational Psychology, 82, 22-32. URL : https://psycnet.apa.org/ doi/10.1037/0022-0663.82.1.22.

Weiner, B. (1985). An attributional theory of achievement motivation and emotion. Psychological Review, 92 (4), 548-573.

\section{References}

Bandura, A. (2000). Teoriia sotsialnogo naucheniia [Theory of social studying]. Sankt-Peterburg : Yevraziia [in Russian].

(C) Kuznietsov Marat, Diab Nabil

DOI (article): https://doi.org/10.32626/2227-6246.2020-48.175-205 
Bek, A., Rash, A., Sho, B., \& Jemeri, G. (2003). Kognitivnaia terapiia depressii [Cognitive Therapy of Depression]. Sankt-Peterburg : Piter [in Russian].

Virtts, U. (2014). Ubiistvo dushi. Intsest i terapiia [The killing of the soul. Incest and therapy]. Moskva : Kogito-Tsentr [in Russian].

German, Dzh. (2015). Psykholohichna travma ta shliah do vyduzhannia. Naslidky nasylstva: vid znushchan u simi do politychnoho teroru [Trauma and Recovery. The Aftermath of Violence - from Domestic Abuse to Political Terror]. Lviv : "Vyd-vo Staroho Leva» [in Ukrainian].

Dzhonson, R., \& Rul, Dzh. (2017). Prozhivaia svoiu neprozhituiu zhizn [Living your unlived Life]. Moskva : Institut obshchegumanitarnykh issledovanii [in Russian].

Diab, N., \& Kuznetsov, M. A. (2019). Strukturnyie osobennosti chuvstva tsennosti sobstvennoi zhizni $u$ studentov [Structural features of students' sense of value of their own life]. Visnyk Kharkivskoho natsionalnoho pedahohichnoho universytetu imeni H. S. Skovorody. Psykholohiia - Notes of H. S. Skovoroda Kharkiv National Pedagogical University. Psychology, 60, 69-93. Kharkiv : HhNPU. Retrieved from https://doi.org/10.34142/23129387.2019.60.04 [in Russian].

Zimbardo, F., \& Boid, Dzh. (2010). Paradoks vremeni. Novaia psikhologiia vremeni, kotoraia uluchshit vashu zhizn [The paradox of time. A new psychology of time that will improve your life]. Sankt-Peterburg : Rech [in Russian].

Kadyrov, R. V. (2012). Posttravmaticheskoie stressovoie rasstroistvo (PTSD): sostoianiie problemy, psikhodiagnostika i psikhologicheskaia pomoshch [Post Traumatic Stress Disorder (PTSD): State of the Problem, Psychodiagnosis, and Psychological Assistance]. Sankt-Peterburg : Rech [in Russian].

Kolesnichenko, O. S. (2018). Zasady boiovoi psykholohichnoi travmatyzatsii viiskovosluzhbovtsiv Natsionalnoi hvardii Ukrainy [Principles of combat psychological traumatization of servicemen of the National Guard of Ukraine]. Kharkiv : FOP Brovin O. V. [in Ukrainian].

Kristal, G., \& Kristal, Dzh. (2006). Integratsiia i samoistseleniie. Affekt, travma $i$ aleksitimiia [Integration and Self-Healing. Affect - Trauma - Alexithymia]. Moskva : Institut obshchegumanitarnykh issledovanii [in Russian].

Kuznetsov, M. A., \& Zotova, L. N. (2017). Zhiznestoikost i obraz zdorovia $u$ studentov [Hardiness and way of students' health]. Kharkov : Izd-vo «Disa Plius». Retrieved from http://dspace.hnpu.edu.ua/ handle/123456789/2952 [in Russian].

(C) Kuznietsov Marat, Diab Nabil

DOI (article): https://doi.org/10.32626/2227-6246.2020-48.175-205 
Kuznetsov, M. A., \& Diab, N. (2020). Temporalnyie prediktory chuvstva tsennosti sobstvennoi zhizni v yunosheskom vozraste [Temporal predictors of a sense of worth of one's own life in adolescence]. Eurasian Scientific Congress. The 1st International scientific and practical conference «Eurasian scientific congress» (January 27-28, 2020). Barcelona, Spain : Barca Academy Publishing [in Russian].

Laktionov, A. N. (2010). Koordinaty individualnoho opyta [Coordinates of individual experience]. Kharkov : KhNU imeni V. N. Karazina [in Russian].

Leontiev, A. N. (1983). Obraz mira [Image of the World]. Izbrannyie psikhologicheskiie proizvedeniia - Selected psychological studies, II, 251-261. Moskva : Pedagogika [in Russian].

Lengle, A. (2019). Voploshchiennaia ekzistentsiia. Razvitiie, primeneniie $i$ kontsepty ekzistentsialnogo analiza. Materialy dlia psikhoterapii, konsultirovaniia $i$ kouchinga [The embodied existence. The development, application and concepts of existential analysis. Materials for psychotherapy, counseling and coaching]. Kharkov : Gumanitarnyi Tsentr [in Russian].

Magomed-Eminov, M. Sh. (1998). Transformatsiia lichnosti [Personality transformation]. Moskva : Psikhoanaliticheskaia Assotsiatsiia [in Russian].

Makklelland, D. (2007). Motivatsiia cheloveka [Human motivation]. Sankt-Peterburg : Piter [in Russian].

Malkina-Pyh, I. G. (2005). Ekstremalnyie situatsii [Extreme situations]. Moskva : Izd-vo «Eksmo» [in Russian].

Mei, R. (2012). Svoboda i sudba [Freedom and Destiny]. Moskva : Institut obshchegumanitarnykh issledovanii [in Russian].

Nartova-Bochaver, S. K. (2008). Chelovek suverennyi: psikhologicheskoie issledovaniie subiekta $v$ yego bytii [Sovereign man: a psychological study of the subject in his being]. Sankt-Peterburg : Piter [in Russian].

Nasledov, A. D. (2013). IBM SPSS Statistics 20 i AMOS: professionalnyi statisticheskii analiz dannykh [IBM SPSS Statistics 20 and AMOS: Professional Statistical Data Analysis]. Sankt-Peterburg : Piter [in Russian].

Padun, M. A., \& Kotelnikova, A. V. (2012). Psikhicheskaia travma i kartina mira: Teoriia, empiriia, praktika [Psychological trauma and the picture of the world: theory, empiricism, practice]. Moskva : Izd-vo «Institut psikhologii RAN» [in Russian].

Seligman, M. (2015). Kak nauchitsia optimizmu: izmenite vzgliad na mir i svoiu zhizn [How to Master Optimism:Change your Mind and your Life]. Moskva : Alpina Pablisher [in Russian].

(C) Kuznietsov Marat, Diab Nabil

DOI (article): https://doi.org/10.32626/2227-6246.2020-48.175-205 
Tarabrina, N. V. (2009). Psikhologiia posttravmaticheskogo stressa: teoriia $i$ praktika [Psychology of post-traumatic stress: theory and practice]. Moskva : Izd-vo «Institut psikhologii RAN》 [in Russian].

Fromm, E. (2002). Iskusstvo liubit. Dusha cheloveka [The art of loving. Human soul]. Moskva : Respublika [in Russian].

Khorovits, L. M., French, R. S., \& Anderson, K. A. (1989). Prototip odinokoi lichnosti. Labirinty odinochestva [The prototype of a lonely personality. Labyrinths of solitude]. Moskva : Progress [in Russian].

Shpranger, E. (2014). Formy zhizni: Gumanitarnaia psikhologiia i etika lichnosti [Life forms: humanitarian psychology and ethics of personality]. Moskva : «Kanon+»; ROOI «Reabilitatsiia» [in Russian].

Jung, K.-G. (2010). Ob energetike dushi [About soul energy]. Moskva : Akademicheskii proekt; Fond «Mir» [in Russian].

Beder, J. (2004). Loss of the assumptive world - How we deal with death and loss. Omega, 50 (4), 255-265. Retrieved from https://doi. org/10.2190/GXH6-8VY6-BQ0R-GC04.

Dweck, C. S., \& Leggett, E. L. (1988). A Social-Cognitive Approach to Motivation and Personality. Psychological Review, 95 (2), 256-273. Retrieved from http://dx.doi.org/10.1037/0033-295X.95.2.256.

Flavell, J. H. (1992). Cognitive Development: Past, Present, and Future. Developmental Psychology, 28 (6), 998-1005.

Janoff-Bulman, R. (1992). Shattered assumptions: Toward a new psychology of trauma. New York : Free Press. Retrieved from https://doi.org/ 10.1080/00029157.1994.10403078.

Olefir, V., Kuznetsov, M., \& Plokhikh, V. (2019). Effect of physical exercises and perceived stress interaction on students' satisfaction with life. Pedagogics, Psychology, Medical-Biological Problems of Physical Training and Sports, 23 (1), 30-35. Retrieved from https://doi.org/ 10.15561/18189172.2019.0105.

Seligman, M. E., \& Maier, S. F. (1967). Failure to escape traumatic shock. Journal of Experimental Psychology, 74 (1), 1-9. Retrieved from https://doi.org/10.1037/h0024514.

Seligman, M. E. P., \& Shulman, P. (1986). Explanatory style as a predictor of productivity and quitting among life insurance sales agents. Journal of Personality and Social Psychology, 50, 832-838.

Skinner, E. A., Wellborn, J. G., \& Connell, J. P. (1990). What it takes to do well in school and whether I've got it: The role of perceived control in children's engagement and school achievement. Journal of Educational Psychology, 82, 22-32. Retrieved from https://psycnet. apa.org/doi/10.1037/0022-0663.82.1.22.

Weiner, B. (1985). An attributional theory of achievement motivation and emotion. Psychological Review, 92 (4), 548-573.

(C) Kuznietsov Marat, Diab Nabil

DOI (article): https://doi.org/10.32626/2227-6246.2020-48.175-205 
Кузнецов Марат, Диаб Набил. Когнитивные предикторы ценности собственной жизни у студентов

\section{АННОТАЦИЯ}

Цель статьи - представить результаты эмпирического исследования чувства ценности собственной жизни (ЦСЖ) у студентов. Под переживанием чувства ЦСЖ понимается направленная активность человека, с помощью которой он укрепляет (усиливает) свое психологическое и личностное бытие. Проверено предположение о важной роли когнитивного фактора в переживании чувства ЦСЖ у студентов. В проявлении ЦСЖ изучена роль такого когнитивного фактора, как базисные убеждения.

Методы. Базисные убеждения диагностировались с помощью модифицированного опросника R. Janoff-Bulman. Для диагностики параметров чувства ЦСЖ использован авторский опросник. В тестировании участвовало 286 студентов. Вычислены корреляции между показателями двух опросников. Использована логистическая регрессия.

Результаты. Такие параметры чувства ЦСЖ, как "Оптимизм», "Здоровье», "Самоконтроль, информация, саморазвитие», "Власть, статус, богатство" и "Близкие отношения, семья, востребованность" оказались тесно связанными с показателями базисных убеждений. Особенно это касается убеждений в справедливости, в позитивном образе «Я», в контроле, в доброжелательности. Выявлены возрастные различия в структуре корреляций между показателями. У студентов старших курсов переживание чувства ЦСЖ как обладания властью, статусом и богатством теснее связано с базисным убеждением в справедливости, чем у студентов младших курсов. Говоря о здоровье, они чаще отмечают важность контроля. Старшие в оценке роли семьи и близких отношений меньше надеются на удачу, чем студенты младших курсов.

Выделены два модуса переживания чувства ЦСЖ - модус "Сближения с людьми» и модус "Дистанцирования от людей». С помощью логистической регрессии вычислен шанс, с которым у студентов тенденция сближения с людьми будет преобладать над тенденцией отдаления от людей. В качестве предикторов в регрессионное уравнение вошли показатели опросника базисных убеждений.

Вывод. Доказано, что преобладание тенденции сближения над тенденцией дистанцирования при переживании чувства ЦСЖ у студентов детерминировано тремя когнитивными предикторами. Это - убежде-

(c) Kuznietsov Marat, Diab Nabil DOI (article): https://doi.org/10.32626/2227-6246.2020-48.175-205 
DOI: https://doi.org/10.32626/2227-6246.2020-48 2020. ВиПУСК 48

ния в справедливости, в контроле происходящего, а также в позитивности образа "Я». Убеждения в доброжелательности окружающего мира и в удаче в число влиятельных когнитивных предикторов чувства ЦСЖ не вошли.

Ключевые слова: ценность собственной жизни, чувство ченности собственной жизни, когнитивный предиктор чувства ценности собственной жизни, параметры ценности собственной жизни, модусы переживания чувства ценности собственной жизни у студентов, базисные убеждения.

\section{Кузнєцов Марат, Діаб Набіл. Когнітивні предиктори цінності власного життя у студентів}

\section{АНОТАЦІЯ}

Mema cmammi - відобразити результати емпіричного дослідження почуття цінності власного життя (ЦВЖ) у студентів. Під переживанням почуття ЦВЖ розуміється спрямована активність людини, за допомогою якої вона зміцнює (підсилює) своє психологічне й особистісне буття. Перевірено припущення про важливу роль когнітивного чинника в переживанні почуття ЦВЖ у студентів. Вивчено роль такого когнітивного чинника, як базисні переконання.

Методи. Базисні переконання діагностовано за допомогою модифікованого опитувальника R. Janoff-Bulman. Для діагностики параметрів почуття ЦВЖ використано авторський опитувальник. У тестуванні брали участь 286 студентів. Обчислено кореляції між показниками двох опитувальників. Використано логістичну регресію.

Результати. Такі параметри почуття ЦВЖ, як “Оптимізм», «Здоров'я», "Самоконтроль, інформація, саморозвиток», "Влада, статус, багатство» $і$ "Близькі стосунки, родина, затребуваність» виявилися тісно пов'язаними з показниками базисних переконань. Особливо це стосується переконань у справедливості, у позитивному образі «Я», у контролі, у доброзичливості. Виявлено вікові відмінності у структурі кореляцій між показниками. У студентів старших курсів переживання почуття ЦВЖ як володіння владою, статусом і багатством тісніше пов'язано з базисним переконанням у справедливості, ніж у студентів молодших курсів. Говорячи про здоров'я, вони частіше відзначають важливість контролю. (C) Kuznietsov Marat, Diab Nabil

DOI (article): https://doi.org/10.32626/2227-6246.2020-48.175-205 http://journals.uran.ua/index.php/2227-6246 
DOI: https://doi.org/10.32626/2227-6246.2020-48 2020. виПУСК 48

Старші в оцінці ролі сім'ї та близьких відносин менше сподіваються на удачу, ніж студенти молодших курсів.

Виокремлено два модуси переживання почуття ЦВЖ - модус «Зближення з людьми» і модус "Дистанціювання від людей». За допомогою логістичної регресії обчислено шанс, із яким у студентів тенденція зближення з людьми переважатиме над тенденцією віддалення від людей. У якості предикторів у регресійне рівняння увійшли показники опитування базисних переконань.

Висновок. Доведено, що переважання тенденції зближення над тенденцією дистанціювання при переживанні почуття ЦВж у студентів детерміновано трьома когнітивними предикторами. Це - переконання у справедливості, у контролі того, що відбувається, а також у позитивності образу «Я». Переконання у доброзичливості навколишнього світу і в удачі до числа впливових когнітивних предикторів почуття ЦВЖ не увійшли.

Ключові слова: цінність власного життя, почуття цінності власного життя, когнітивний предиктор почуття цінності власного життя, параметри цінності власного життя, модус переживання почуття цінності власного життя у студентів, базисні переконання.

Original manuscript received February 10, 2020 Revised manuscript accepted March 04, 2020 